inflated; colors similar but the transversal yellow bands larger and on the $3^{\mathrm{d}}$ and $4^{\text {th }}$ segments extended into a median dorsal line; last segment short, black, shining, with a flat basal impression; appendages as long as the segment, converging, cylindrical, rounded on tip, black, hairy ; part hetween them large, black rounded. Vulvar lamina large, broad, a little shorter than the segment, split to the basal third, pointed, tapering gradually to the tip, yellow; cavity bordered by it black, with an elevated ridge, pointed in iniddle.

Length
Abdomen
Ala sup.
Ala inf.
Pterostigma
Femur post.
Appendages

$\begin{array}{cc}\text { Male } & \text { Female } \\ 34 & 33 \\ 24 & 20-23 \\ 22 \frac{1}{2} & 23 \\ 22 & 2 \mathrm{I} \frac{1}{2}-22 \frac{1}{2} \\ 2 & - \\ 5 & 5 \\ 1 \frac{3}{4} & \mathrm{I}\end{array}$

Male Female

Exp. ala

Lat. cap.

Breadth ant.

" post.
48

$6 \quad 5^{\frac{1}{2}}$

6

7

Habitat : Center, N. Y.. Mr. J. A. Lintner, no. 2839, 27 May, $4 \delta^{\star}$; 2840, 2 I May, 49 . Two females (L. vacua Hagen, no descr.) from Saskatchewan, Lake Winnipeg, collected in 1860 by Robert Kennicott. The position of this rather eccentric, small species is near $C$. ulheri, but it is separated from that species by unusual characters. The anal angles of the hind wings of the male are nearly rounded; all triangles are without transversal veins: only one series of discoidal cells, and a very plain venation. It is very interesting that this apparently arctic species is found in eastern New York.

\title{
DESCRIPTIONS OF SOME NEW NORTH AMERICAN DOLICHOPODIDAE.
}

BY William M. WHEELER, MILWAUKEE, WiS.

(Concluded from. $p .3^{62}$.)

Peloropeodes, n. gen.

§. Small dull metallic green species. Palpi prominent, though not enlarged. Antennae as long as the head and thorax; first joint stout, subcylindrical, glabrous on its upper surface, with a few hairs on its under side; second joint short, rounded, subcalyculate; third joint pubescent, very long, tapering from a broad rounded base to a blunt point, on which is inserted the thick, flexible arista. Face rather broad for a male, front ample. Thoracic dorsum moderately arched, beset with the usual stout setae; scutellum broad, short, smooth, with four setae. Abdomen with six segments, short, stout at the base but tapering very rapidly to the apex, where is attached the sessile and greatly enlarged hypopygium, consisting of a scuttle shaped box, two thirds the size of the abdomen, from the ventrad directed opening of which protude several hook-shaped chitinous appendages. Legs rather stout. hairy; tibiae equalling the femora in length; spurs of the fore tibiae short, those of the posterior pairs 
of medium size; tarsi of all the feet somewhat longer than the tibiae; hind metatarsal joint without bristles. Wing somewhat longer than the body, slightly pointed; anal angle obtuse; fourth longitudinal vein slightly bent, entering the tip of the wing and scarcely inclined towards the end of the third longitudinal vein; second and third longitudinal veins straight, parallel; fifth longitudinal vein evenly curved. entering the posterior margin somewhat nearer the base than the apex of the wing; posterior cross vein perpendicular to the hind margin, distant about twice its length from the tip of the fifth longitudinal vein; sixth longitudinal vein short. distinct.

$q$ of the same color as the male. Face rather broad, not attaining to the lower margin of the eyes. Antennae differing profoundly from those of the male; especially in respect of the third joint and its arista; the former being very short, semioval and flattened laterally, while the latter, inserted dorsally, and clothed with microscopic pubescence, is solong that if reflexed it would reach to the middle of the thoracic dorsum. Front ample; ocelli prominent. The rather large ovipositor, much exserted in all of $\mathrm{my}$ specimens, terminates in a comb-like organ with regular, short, blunt teeth.

(Generic name derived from $\pi$ í $\lambda \omega$ pos, enormous, and $\pi \epsilon \omega \delta \eta \eta$, provided with a large penis.)

\section{Peloropeodes salax, n. sp. $\delta$. $q$.}

Length : $\delta 2.25 \mathrm{~mm}$; $q 2 \mathrm{~mm}$; length of wing of $2.5 \mathrm{~mm}$., $q 2.25 \mathrm{~mm}$.

Dull metallic green. Palpi black. Face and front metallic green, almost obscured by whitish dust. Antennae black; pubescence of the elongated third joint of the male, whitish; bristles of the superior orbit black, those of the inferior orbit white. Thoracic dorsum dark metallic green, but so thickly covered with yellow dust, as to be subopaque in the male, opaque in the female; this dust is thickest on the anterior half of the thorac- ic dorsum; scutellum dusted with white with a metallic violet reflection; pleurae opaque, rather thickly covered with white dust. Cilia of the tegulae long, yellow. Metallic green ground color of the abdomen somewhat concealed by whitish dust; all the segments covered with sparse short black hairs; capsule of the hypopygium black, subopaque, with short appressed whitish pubescence on its lateral faces and a few short, irregularly placed setae in the median dorsal line; the numerous hook-like appendages pale yellow; ovipositor of the female yellowish red; teeth of its comb-shaped tip black. Fore coxae entirely yellow, beset towards their apices anteriorly with a few stout black hairs; posterior coxae with infuscated bases. Legs pale yellow, covered with rather stout black hairs, arranged in very regular rows on the tibiae; the posterior pairs have three spines on their posterior faces. Tarsi blackened from the tip of the first joint. Halteres yellow. Wings uniform grayish hyaline, somewhat pointed; base lanceolate; the portion of the fourth longitudinal vein beyond the posterior cross vein but very slightly bent, its end running parallel with that of the third longitudinal vein.

Habitat : Milwaukee Co., Wis.

I have taken two males and three females of this species in a damp and rather dense wood where the undergrowth consisted very largely of Boehmeria cylindrica and Impatiens fulva.

Chrysotimus pusio, Loew. $\delta$.

A number of females of this species captured on the foliage in damp woods near Milwaukee, agree with Loew's description except in the color of the antennae. According to Loew the antennae are "entirely black," whereas in all my specimens the two basil joints are honey yellow, while the third joint is 
fuscous. The tergum of the last abdominal segment is also more blackish than metallic green. These differences are probably to be attributed to local variation. I subjoin a description of the male, which seems to have been unknown to Loew and which differs from the female in much the same manner as the male of the European Chrysotimus molliculus, Fallen, differs from its female.

Length : I. $5^{-1.75} \mathrm{~mm}$; length of wing 2.5 $\mathrm{mm}$.

Bright golden green. Palpi blackish. Antennae with their two basal joints honey yellow; third joint fuscous, covered with distinct pale hairs. Cilia of the inferior orbit white; hairs and setae covering all other portions of the body honey yellow. The vivid metallic green of the thoracic dorsum and pleurae dimmed somewhat by a layer of whitish dust. Abdomen bright metallic green (venter yellowish?) of a shade differing from that of the thorax in being somewhat less golden and less subdued; hypopygium large and conspicuous; its outer portions brown, its inner appendages yellow. Legs honey yellow, the last tarsal joint on all the feet fuscous or black. Halteres yellow. Wings grayish hyaline. suffused with yellow, especially at their bases; veins honey yellow.

The six males before me were taken in company with the females of Loew's C. pusio; hence I believe there can be no doubt about their identity, especially since the relation that the sexes bear to each other is the same as that observed in the case of $C$. molliculus. My specimens have collapsed in drying so that I am unable to decide whether the ven. ter is yellow, as in the European species.
Aphantotimus, n. gen.

§. . . Minute metallic green species, with rather thin integument, collapsing when dry; setae covering the body yellow; sexes alike in coloring. Palpi of moderate size. Antennae alike in both sexes; first joint short, smooth; second short and broader, provided with the usual hairs; third joint small, narrower than the second, spheroidal, with rather long, apically inserted and microscopically pubescent arista. Face rather broad in both sexes, narrowed below, not reaching to the lower corners of the eyes. Head situated rather deep on the thorax to which it seems to be closely applied. Thorax resembling in its shape the thorax of Chrysotimus; in the prescutellar region there is an extensive though shallow indentation, the exact shape of which my dried and collapsed specimens do not enable me to determine. Abdomen laterally compressed, in the male of six segments, tapering rapidly; hypopygium very large, pedunculate, distinctly flexed under the venter, capsule hood-shaped, with exserted appendages; a pair of these, apparently homologous with the lamellae of the hypopygium of Dolichopus and Gymnopternus, are disk-shaped and fringed with cilia; ovipositor large, usually exserted, resembling that of Chrysotimus. Legs rather smooth, with short and appressed spines; tibial spurs feebly developed; in the spinulation of the legs little or no sexual differences. Wings thin, hyaline, rather large; costa rather prominently arcuate; anal angle not very prominently projecting. Neuration resembling that of Chrysotimus; posterior cross vein more than twice its length distant from the border of the wing; fourth longitudinal vein gently bent beyond the posterior cross vein, and ending at or a little in front of the tip of the wing. With this vein the third longitudinal vein runs parallel and is in one species nearer to it than to the second longitudinal vein; second and third longitudinal veins presenting the same gentle curvature as the fourth. 
(Generic name drived from äфavтos, forgotten, and $\tau \mu \eta^{\prime}$, honor.)

The species of Aphantotimus resemble the chrysotimi in having yellow hairs and setae; in the prescutellar indentation, in the neuration of the wings and in the apical insertion of the antennal arista. The females, however, resemble the males in coloring, and do not have the abdomen largely yellow. The hypopygium of Aphantotimus is disengaged and very large, thus resembling that of the higher genera like Dolichopus and Gymnopternus; while the hypopygium in Chrysotimus is small and partly embedded. There are also differences in the size and shape of the third antennal joint; though this character is not of generic value.

The two minute species here described, differ considerably in the structure of the hypopygium, but to just what extent I have not ascertained, as this organ must be examined in recently killed specimens. Their close resemblance in other respects. e. g. in the structure of the antennae, neuration of the wings, shape of the body and covering of yellow hairs, leads me to unite them in the same genus.

Aphantotimus willistoni, n. sp. $\delta$. $q$.

Length $1.5^{-1.75} \mathrm{~mm}$; length of wing 1.5 $\mathrm{mm}$.

Palpi pale yellow. Face metallic green, smooth; covered with a thin layer of yellowish dust, composed of minute scales that are clearly discernible, and not closely aggregated. Antennae entirely black, inclining to piceous or brown when viewed from their apices; third joint somewhat conical at the insertion of the arista and covered with scarsely perceptible pubescence. Front rather broad, blackish green, covered with the same dust as the face; frontal setae and those of the thorax and abdomen pale yellow; cilia of the inferior orbit yellow. Thoracic dorsum and scutellum golden green, overlaid with yellow dust, consisting of minute scales; pleurae bright golden green, less dim than the thoracic dorsum, growing black in the region of the tegulae. Cilia of the tegulae yellow. Abdomen bright metallic green, with a more violet than golden reflection; covered with short and stiff yellow hairs ; in the female the exserted ovipositer is orange yellow; in the male the large hoodshaped hypopygial capsule is shining black, changing to metallic green in some lights; appendages pale yellow; the two lamellae rounded, fringed with yellow cilia; a long and exposed blade-shaped organ (the penis?) extends from the base to the tip of the hypopygium on the ventral side. Legs pale yellow; tips of the tarsi scarcely darker, covered with short brown hairs, which turn to yellow in some lights. In the male the fore coxae are fuscous anteriorly and basally; the posterior coxae are fuscous with yellow tips; in the female the coxae are largely pale yellow, there being only a large fuscous spot at their bases. Halteres large, yellowish white. Wings brownish hyaline with brownish veins; the third and fourth longitudinal veins parallel, and more approximated to each other than the third longitudinal vein is to the second.

Habitat : Milwaukee Co., Wis.

The single male and three females in my collection were taken on the foliage in a swampy wood in company with hundreds of Dolichopods belonging to the genera Dolichopus, Pelastoneurus, Sympycnus, Psilopus and Chrysotus.

Aphantotimus fraterculus, n. $\mathrm{sp} . \delta$. $q$.

Length I-I.5 mm.; length of wing I.25 $\mathrm{mm}$. 
Palpi brown, with white hairs. Face, front and occiput metallic green, covered with yellowish dust, the separate scales composing which are distinctly discernible as in the preceding species. Antennae black, resembling in structure those of $A$. willis. toni. Cilia of the inferior orbit yellow. Thoracic dorsum bright metallic green with bluish reflection; the thin covering of dust and the comparatively few setae yellow; prescutellar depression very distinct, somewhat v-shaped; pleurae vivid metallic green, covered with a thin layer of yellow dust, Tegulae pale yellow, cilia yellow, changing to brown in some lights. Scutellum and abdomen vivid metallic green with violet and cupreous reflections, the rather long hairs on the latter pale yellow; venter and hypopygium black, the latter roughened, metallic green dorsally; appendages pale yellow. The capsule of the hypopygium is narrower and somewhat longer than in the preceding species; the long, blade-shaped appendage dark brown; the two lamellae dirty yellow with black tips, apparently without cilia on their edges. In the male, coxae and legs black, the former with yellow, the latter with black hairs. Femora with a faint metallic green luster; knees broadly yellow; trochanters, inner faces of the tibiae and bases of the separate tarsal joints dirty yellow. In the female the femora and tibiae are bright metallic green, the knees and trochanters yellow, the tarsi black. Halteres pale yellow. Wings faintly brownish hyaline; third and fourth longitudinal veins less approximated than in the preceding species; perfectly parallel and but very slightly curved from the posterior cross vein on. The fourth longitudinal vein terminates in the tip of the wing.

Habitat : Milwaukee Co., Wis.

This species is very readily distinguished from $A$. willistoni by its smaller size, the more bluish and less golden reflection of its metallic surfaces, its dark-colored legs and the neuration of the wings. Three males and one female were taken with the preceding species.

\section{Xanthochlorus helvinus, Loew. $\delta$.}

Loew felt some doubt as to whether this species, which he described from female specimens only, was not merely a variety of the European $X$. tenellus, An examination of a number of males taken by me in several localities in the vicinity of Milwaukee, seems in no way to invalidate the species. In these specimens I can detect no green markings whatsoever. The general honey yellow color of the body is departed from only on the cheeks and front, which are has gray and on the pleurae, where I find two clearly defined black spots; one larger and more pronounced just back of the tegula and another smaller and more oval spot (not mentioned in Loew's description) on the metathorax just beneath the lateral edge of the scutellum. The powerful bristles on the head and thoracic dorsum, as well as the cilia of the tegulae and the hairs covering the other portions of the body are dark brown, almost black, thus contrasting with the yellow body color. The hypopygium is prominent, though hardly " dick angeschwollen" as is the case in the European $X$. tenellus, Wied, according to Schiner. The acute hypopygial appendages scarcely project and are honey yellow. The bases of the second, third and fourth abdominal segments are infuscated in dried specimens. 
HYDROPHORUS PHILOMBRIUS, n. sp. $\delta$.

Length $3.5 \mathrm{~mm}$.; length of wing $4 \mathrm{~mm}$.

Dull olive green. Face bright metallic green, covered with white dust, which scarcely dims the brilliant ground color, except on the oral margin, where it is aggregated to form two spots, one on each side abutting on the orbit. Cheeks and palpi black, clothed with short appressed yellow pubescence; the pubescence on the eyes short and silvery white. Antennae black, pubescence on the third joint white, tip of the robust arista pale. Front and occiput of a blackish ground color, covered with glistening white dust which gives them a frosted appearance; cilia of the superior orbit black; those of the inferior orbit glistening white, but becoming tawny near the oral orifice. Thorax, scutellum and abdomen covered with the same frost-like dust as the front; as this dust, which consists of microscopic scales, is wanting about the insertion of each seta, the surface has a spotted appearance. The disk of the thoracic dorsum is crossed by four longitudinal shining purple bands, the outer pair being slightly broader than the inner: the spaces between these bands are vivid metallic green. Scutellum bearing four rather long black bristles; its median portion golden green, the lateral portions coppery red. Pleurae dull olive green, more olive brown towards the insertions of the coxae. Tegulae honeyyellow, with glistening white cilia. Abdomen olive green, in rear view more bluish; the rows of impressed dots along the tergal edges shining black; the sparse hairs covering the terga of the basal segments and the whole venter, glistening white; hypopygium black, concealed, appendages not apparent in my specimen. Legs and coxae covered with white dust; the fore pair of legs black; fore coxae dull metallic green, fore femora incrassated in the usual manner and bearing a few long spines at their bases on the under side; on the hind face of the distal two thirds of the fore tibiae there is an even comb of stout black spines; apical claw distinctly marked though not acute; the distal half of the fore tibiae and black tarsi with short and dense white pubescence. Posterior femora and tibiae slender, vivid metallic green; posterior tarsi with white pubescence somewhat more scattered than on the fore tarsi. Pulvilli and empodia of all the feet white, fringed with silvery hairs. Halteres bright honey yellow, the base of the peduncle somewhat infuscated. Wings long and narrow, costal and posterior margins parallel, uniformly grayish hyaline; veins black, becoming yellow near the insertion of the wings; third and fourth longitudinal veins gently approximating near the tip of the wing, but again diverging slightly at their juncture with the costa; sixth longitudinal vein very short and incomplete.

Habitat : Milwaukee Co., Wis.

This large and beautiful species seems to be related to the Alaskan Hydrophorus innotatus, Loew. It may be distinguished by the white dust on the face and front, the glistening white cilia of the inferior orbit, the vittate thoracic dorsum, the bright yellow halteres and the yellow bases of the nervures of the wing.

It is possible that the species which I here call $H$. philombrius is one of the two species mentioned by Baron v. Osten Sacken (Western Diptera p. 320.) "One from Webber Lake, Sierra Nevada (July 25) is allied to $H$. innotatus, Loew from Sitka (Monogr. 2 p. 212) in the coloring of the face, the upper part of which is greenish, and in other characters; its halteres, however, have a yellow, and not an infuscated knob. The other species, taken near Santa Barbara (January 25 ), is easily distinguished by the 
color of its first longitudinal vein, which is brownish yellow; the costa be- yond the insertion of the first vein is of the same color."

\section{Entomological Notes.}

Prof. F. H. Snow has been elected chancellor of the Kansas State University at Lawrence. Princeton College at commencement last June conferred the degree of LL. D. upon Chancellor Snow.

Junonia coenia.- In a letter to Mr. S. H. Scudder, Mr. Justus W. Folsom writes "On 30 July r 890 I saw an unmistakable specimen in Cambridge, Mass., on flowers of $\mathrm{Nep}^{-}$ eta cataria bordering the Charles river. The insect was apparently in perfect condition."

Mr. C. J. Maynard's work on the butterflies of North America will make an octavo volume of about 200 pages, illustrated with many wood-cuts. The descriptions are short and comparative. De Wolfe, Fiske \& Co. of Boston are the publishers.

Mr. H. T. Fernald, a son of Prof. C. H. Fernald, of the Massachusetts Agricultural College, has completed a post graduate course in biology at the Johns Hopkins University, receiving the degree of $\mathrm{Ph}$. D., and has been elected professor of zoölogy in the Pennsylvania state college. The Johns Hopkins University Circular (No. 80 April 1890) contains his "Studies in thysanuran anatomy," a preliminary communication.

British Orthoptera. The July issue of the Entomologist's monthly magazine contains the conclusion of Mr. Eland Shaw's "Synopsis of British orthoptera." The list of species includes,

6 Forficulidae,

7 Blattidae,

I4 Acrididae,

Io Locustidae and

5 Gryllidae, a total of 42 species. of which 3, Anisolabis maritima, Phaneroptera falcata and Oecanthus pellucens are included with some doubt. The synopsis was commenced in the number for August 1889, and altogether fills a little over 50 pages.

Neuroptera of Ireland. In his catalogue of the neuroptera of Ireland (Proc. \& Trans. nat. hist. soc. Glasgow, r 890, n. s. v. 2, p. 259-292) Mr. James J. F. X. King gives the following comparative summary of the genera and species of neuroptera occurring in Ireland, Great Britain and Belgium.

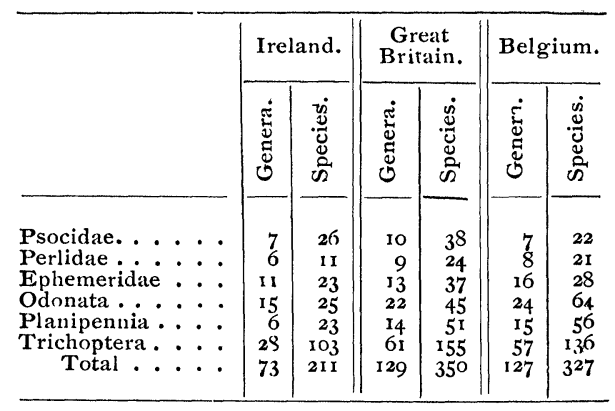

Termites INJURIOUS TO GROWING TREes. - Mr. Henry Tryon mentions (Queensland Department of agriculture, Report on insect and fungus pests, No. I, p. 228-229) that complaints concerning injuries to growing trees by termites are common in the western and northern parts of the colony. The termites find their way into the tree through some accidental opening or weak spot; frequently they start at the collar of the tree or just at the surface of the ground and thence work upwards.

Mr. Tryon does not identify the species; he states that all kinds of shade and fruit trees are attacked except those belonging to the orange family. In Florida termites frequently injure orange trees though old and well established trees are little liable to their attacks. 

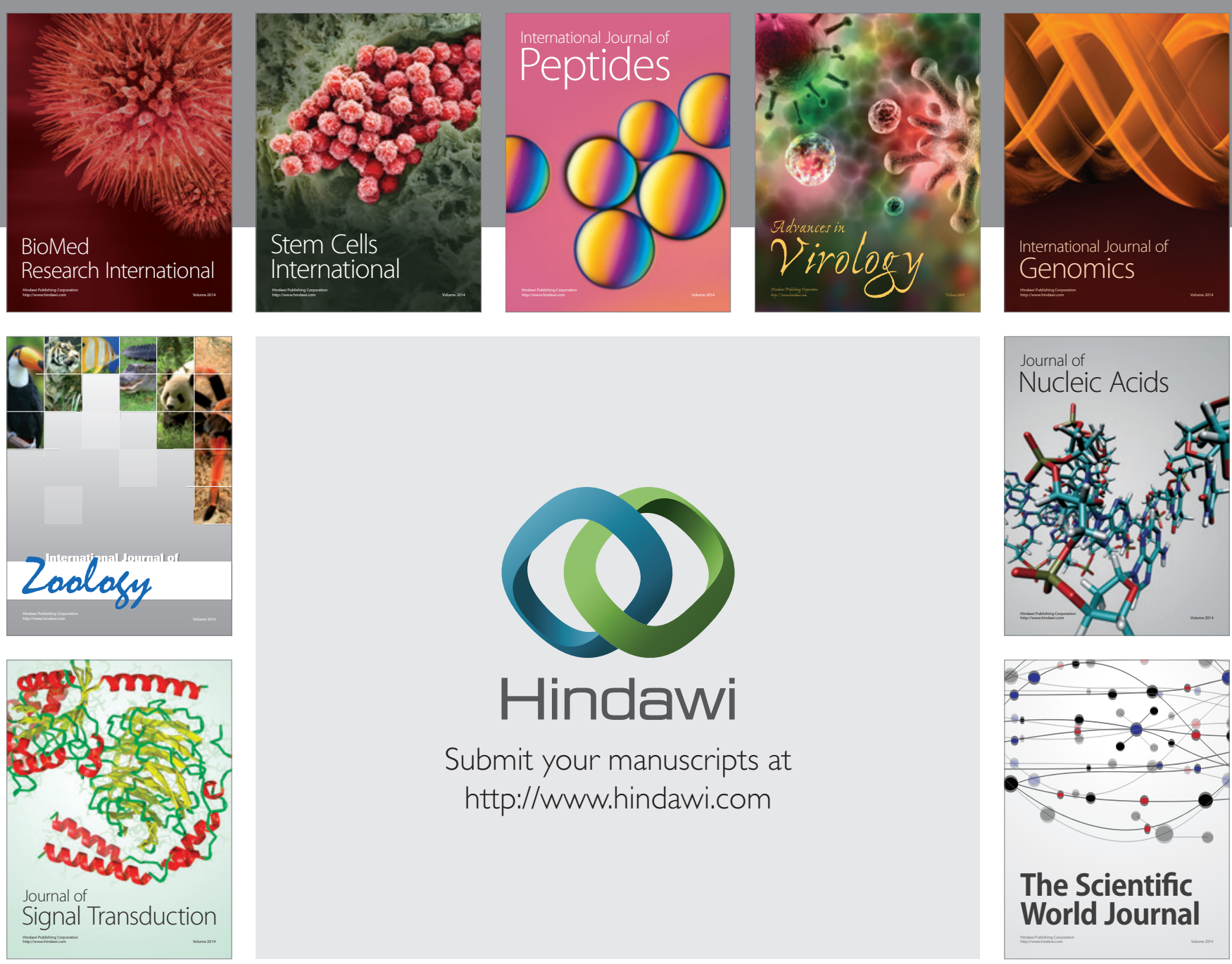

Submit your manuscripts at

http://www.hindawi.com
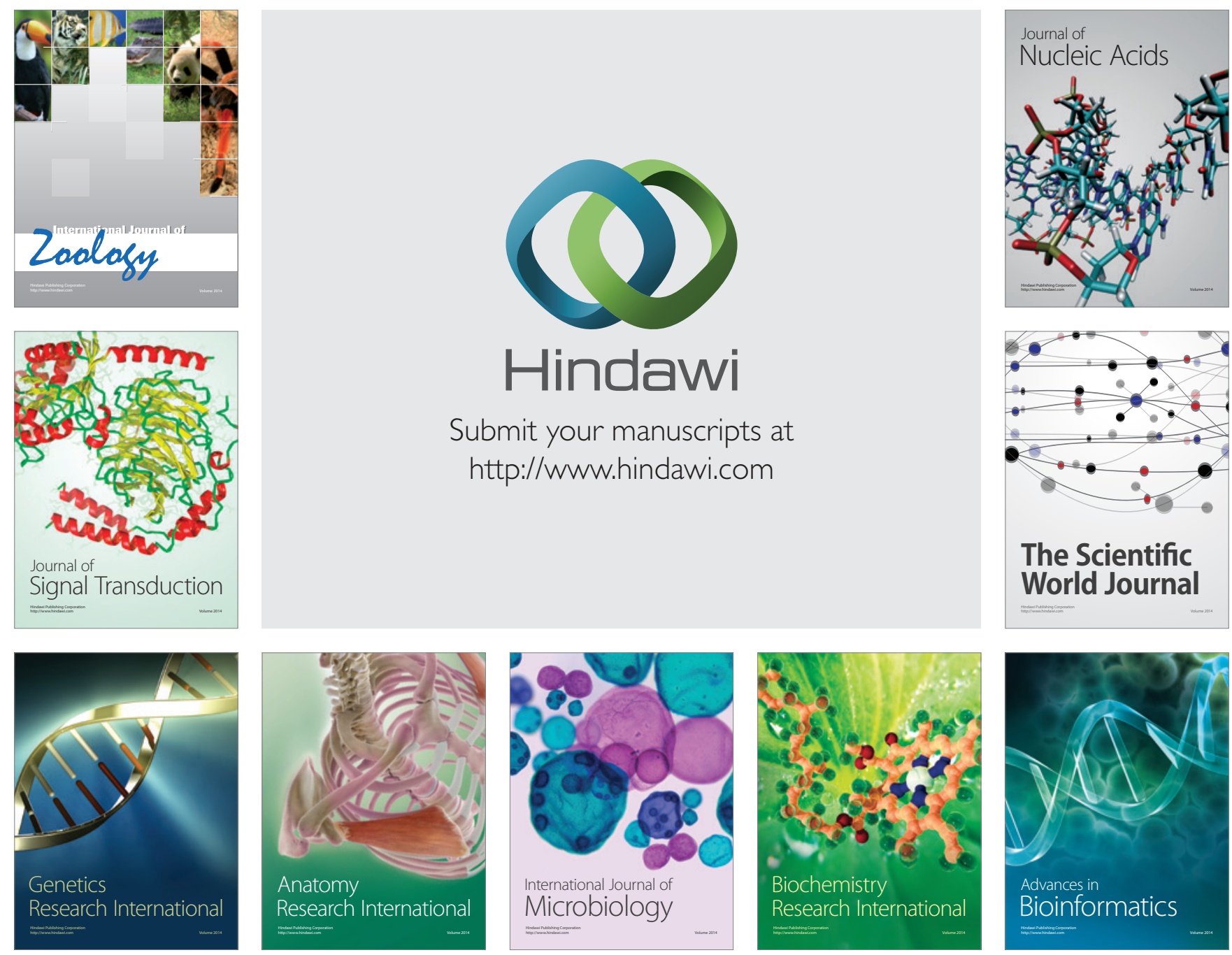

The Scientific World Journal
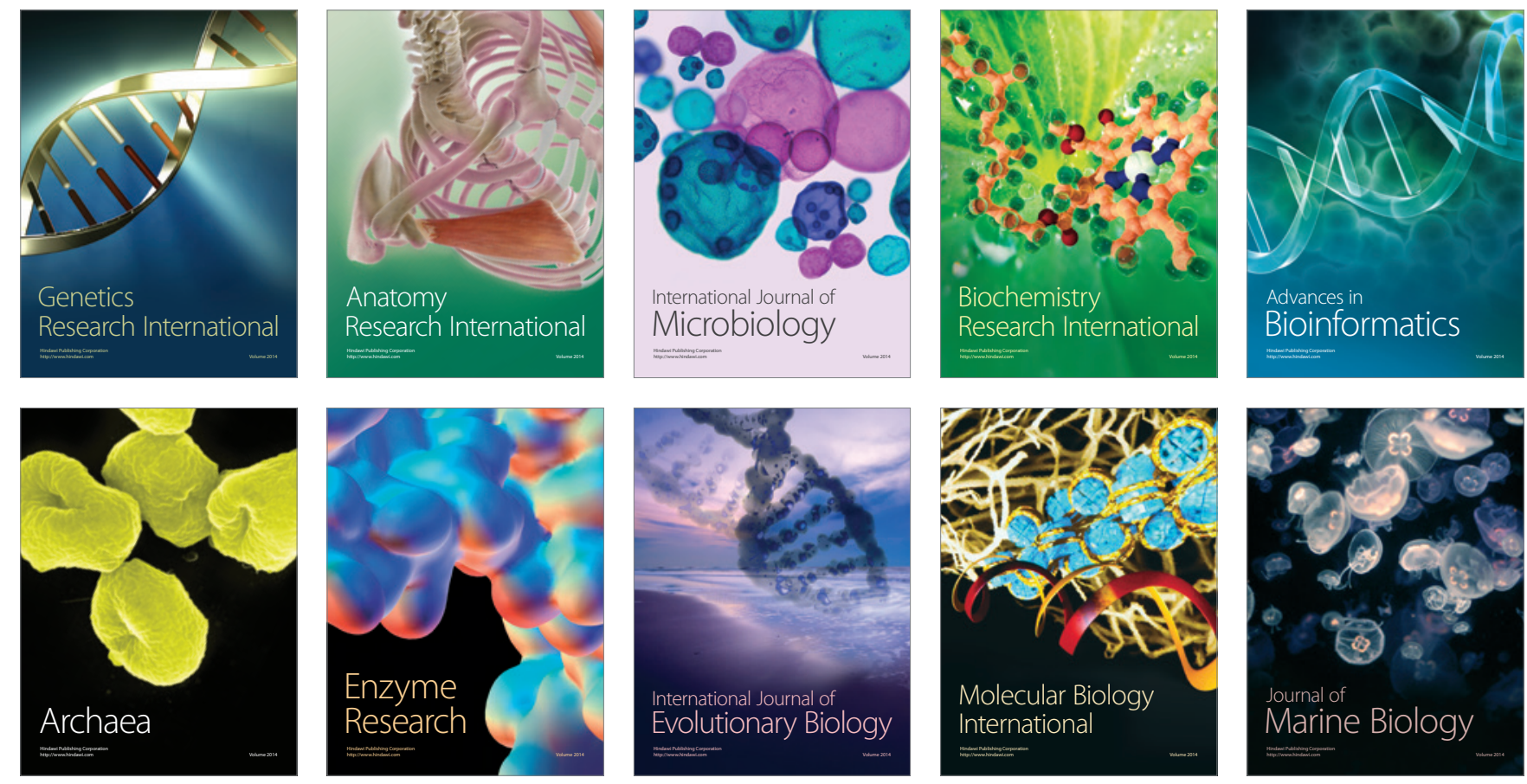